OPEN ACCESS

\title{
Rethinking the Innovation Approach in Developing Countries
}

\author{
Yoslan Nur \\ Division for Science Policy and Capacity Building, Natural Sciences Sector, UNESCO
}

\begin{abstract}
As reflected in the title, the main objective of the paper is to explore an appropriate approach to promote technological innovation for developing countries. Aiming to this goal, the paper studies three main innovation system approaches, whose implantation is being attempted in developing countries: first, national innovation systems (NIS), which was developed in OECD countries; second, the system of innovation for development (SID), which is a concept that tries to adapt NIS to developing countries; and third, inclusive innovation which is a pro-poor innovation system. Based on the strengths and the weaknesses of each concept and their potential adaptation in developing countries, the paper proposes an integrated approach of innovation system for developing countries. Compared to developed countries, the concept of innovation system in developing countries should be more complex because it involves not only the formal sector such as enterprises, universities, research institutes, government, and financial system but it also involves NGOs, informal companies, grassroots inventors, local and indigenous knowledge, etc. The last part of the paper discusses the ideas that innovation stakeholders in developing countries can use to promote their proper innovation system.
\end{abstract}

Keyword: Innovation policy, National innovation system, Inclusive innovation, Innovation concept, Developing countries, Innovation system for development, Grassroots innovation

\section{INTRODUCTION}

Innovation occupies a very important place in our society. On the one hand innovation is considered as a critical factor in enhancing economic growth and competitiveness; and on the other hand innovation is considered as a crucial element for social cohesion, equality and poverty alleviation. Innovation might also be seen as a way to solve important problems relating to pollution, energy and urbanism. Yet the main focus of innovation is to create economic wealth (Lundvall and Borras 2005).

Since the early 1990s, the concept of a national innovation

*Correspondence to : Dr Yoslan Nur

Programme Specialist, Division for Science Policy and Capacity Building, Natural Sciences Sector, UNESCO

E-mail : y.nur@unesco.org

World Technopolis Review

Copyright $\odot$ World Technopolis Association

CC This is an open-access article distributed under the terms of the Creative Commons Attribution Non-Commercial License(http://creativecommons.org/licenses/by-nc/3.0) which permits unrestricted noncommercial use, distribution, and reproduction in any medium, provided the original work is properly cited system (NIS) has attracted the attention of many policymakers. The concept has gained much intellectual and practical coherence over the previous decades and has been adopted by the OECD, the European Commission, UNCTAD and developed countries. The NIS was widely diffused in all corners of the world, including in developing countries. For more than a decade, NIS has increasingly become the focus of a means to address some of the more profound issues for developing nations. The NIS was developed in OECD countries. Its implementation in developing countries varied greatly based on reactions from scholars. Some of them completely rejected the notion and certain scholars proposed an adaptation to the concept to take into account the local, social, economic and political situation of developing countries.

On the hand, there is also a similar initiative to promote innovation in developing countries, for example grassroots innovation, with the ambition to use innovation to improve the productivity and livelihoods of people. Little is known about innovation, technological development, entrepreneurships 
and the dynamics and changes that take place between sectors, and their relationship with economic and social changes in developing countries. However, there is an increase of interest in promoting this type of inclusive innovation.

The main purpose of the paper is to explore an appropriate approach to promote technological innovation for developing countries. The elaboration of new mechanisms shall require the analysis of current approaches and existing practices to (1) understand the limitation of each concept, (2) understand the current constraints faced by the main actors and (3) propose new possible mechanisms to make innovation work in developing countries.

The paper will begin with an introduction and be followed by a discussion about the nature and the limitation of the three main innovation system approaches whose implementation is being attempted in developing countries: first, national innovation systems (NIS), which was developed in OECD countries; second, the system of innovation for development (SID), which is a concept that tries to adapt NIS to developing countries; and third, inclusive innovation which is a pro-poor innovation. To end, the paper proposes an integrated approach to promote innovation in developing countries.

\section{NATIONAL INNOVATION SYSTEM - DIFFICULTIES IN ITS IMPLEMENTATION IN DEVELOPING COUNTRIES}

The majority of science, technology and innovation (STI) policy specialists agree that notion of the National Innovation System (NIS) is based on the research of Freeman (1987), Lundvall (1992) and Nelson (1993). These researchers are considered the founding fathers of the NIS. According to Benoit Godin, the NIS concept is rooted on the system approach which was developed by the OECD back in 1960 along with the notion of the system dynamic and system analysis which were popular at the time (Godin 2007). Godin also explains that many researchers, particularly concerning management, began to use a system approach to study decisions and choices regarding STI at the end of 1950s. Therefore, the NIS concept is not completely new. However, he recognizes that that OECD has been a very early and systematic user of system approach. Lundvall - Deputy Director of the OECD Directorate for Science, Technology and Industry from 1992 to 1995 - set up the concept of NIS in OECD.
To date, there is no single accepted definition of a NIS. However there is a semantic core that appears in most of the definitions. Box 1 outlines some of the definitions.

Box 1. National innovation systems: definitions

A national system of innovation has been defined as follows:

".. the network of institutions in the public and private sectors whose activities and interactions initiate, import, modify and diffuse new technologies." (Freeman 1987)

".. the elements and relationships which interact in the production, diffusion and use of new, and economically useful, knowledge ... and are either located within or rooted inside the borders of a nation state." (Lundvall 1992)

"... a set of institutions whose interactions determine the innovative performance ... of national firms." (Nelson 1993)

".. the national institutions, their incentive structures and their competencies, that determine the rate and direction of technological learning (or the volume and composition of change generating activities) in a country." (Patel and Pavitt 1994)

".. that set of distinct institutions which jointly and individually contribute to the development and diffusion of new technologies and which provides the framework within which governments form and implement policies to influence the innovation process. As such it is a system of interconnected institutions to create, store and transfer the knowledge, skills and artefacts which define new technologies."(Metcalfe 1995)

Source: OECD (1997)

Based on these definitions, we can conclude that the basic notion of the NIS is a set of interrelated institutions; its core is made up of those institutions that produce, diffuse and adapt new technical knowledge, be they industrial firms, universities, or government agencies. The links between these institutions consist of flows: knowledge, financial, human (people being the bearers of tacit knowledge and knowhow), regulatory, and commercial.

\section{The basic characteristics of the NIS are as follows:}

A. The NIS adopts the systemic approaches as opposed to the linear model of innovation. In the linear model, knowledge flows are modeled quite simply: the initiator of innovation is science and an increase in scientific inputs into the pipeline will directly increase the number of new innovations and technologies. In reality, ideas for innovation can come from many sources and at any stage of research, development, marketing and diffusion. Innovation can take many forms, including adaptations of products and incremental improvements to processes (OECD 1997). This systemic 
approach is also arguably better suited for policymakers as it allows them to identify leverage points or weak links within the network. NIS is holistic and interdisciplinary. The operation and governance of an NIS is interdisciplinary in nature, in terms of technology convergence as well as administration. NIS covers all the technologies that operate in the nation and draws from all ministries and departments, though the science and technology (S\&T) ministry might take the lead in the design of an NIS.

B. Innovation is the focus of national innovation system. It is the result of a complex interaction between various actors and institutions. Lundvall pointed out that "innovation is a ubiquitous phenomenon in the modern economy. In practically all parts of the economy, and at all times, we expect to find on-going processes of learning, searching and exploring, which result in new products, new techniques, new forms of organization and new markets." He underlined that innovation is both gradual and cumulative, and is a process rather than a stage. Therefore innovation is not merely an individual act of learning by a firm or entrepreneur, but is situated within a larger system that both enables and draws on the innovative process (Lundvall 2000).

C. There is a flow of knowledge in the NIS. There are many channels and mechanisms through which knowledge can flow among the institutions. Principally, there are four basic knowledge flows among actors in a national innovation system: 1) interactions among enterprises; 2) interactions among enterprises, universities and public research laboratories; 3) diffusion of knowledge and technology to firms; and 4) movement of personnel (OECD 1997).

D. The NIS is the networking of the firms, public research institutes, universities, financial institutions, educational system government regulatory bodies and others. They are interdependence each other. In the systems approaches, overall innovation performance of an economy depends not so much on how specific formal institutions (firms, research institutes, universities etc.) perform, but on how they interact with each other as elements of a collective system of knowledge creation and use, and on their interplay with social institutions such as values, norms, legal frameworks, and so on (Smith 1994). The linkages among the stakeholders involved in innovation are key to improving technology performance.
Between 1994 and 2001, the OECD conducted two phases of projects on NIS. The OECD countries have been using the NIS concept without much difficulty due to the fact that it was developed in OECD countries. However, many scholars have been questioning the implementation of NIS in developing countries. Taking in consideration the nature of the NIS concept, its implementation in developing countries is problematic, as shows the below synthesis.

$\underline{\text { First, }}$ with regards to the systemic approach, there are three issues that make the implementation of the NIS difficult in developing countries:

- The key science and technology institutions of the innovation system which are often analyzed in developed countries, such as universities, research institutes and laboratories, are missing or inadequate (Pietrobelli and Rabellotti 2009). If any, there is lack of capacity to conduct advanced research (Chaminade et al. 2010). The absence or inadequacy of these institutions raises an important systemic problem.

- The developing countries have a large number of microenterprises operating in the informal sector. NIS does not take in consideration the informal sector meanwhile it is an important economic player in developing countries.

- Non-Governmental Organizations (NGOs) play an important role in promoting grassroots innovation in many developing countries. Unfortunately, NIS has not foreseen the role that they can play in NIS.

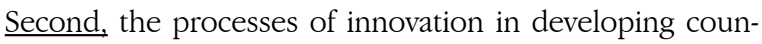
tries are of a different nature in comparison with developed countries: incremental innovations and absorption of knowledge and technologies new to the firms are more frequent and relevant in developing countries than radical innovations that are new to the world. While the analysis of NIS in industrialized economies has increasingly focused on R\&D and frontier innovation, in most LDCs, the nature of innovation is quite different (Pietrobelli and Rabellotti 2009). Furthermore, NIS focuses only on firm based innovation and neglects the grassroots innovation which has an immense potential for wealth creation and which meet the need of economically disadvantaged people. Currently, there are many successful grassroots technological innovations in developing countries, unfortunately, so far, the economic impact of these innovations has been low. 
Third, regarding the flow of knowledge, as the system has very limited capacity in creating knowledge, the inflows of knowledge and technology from external sources are essential components in the innovation and learning process in the developing countries. There is a more or less important number of foreign-based firms which tend to be disconnected from the rest of the economy.

Fourth, on the contrary to the developed countries, as a whole, developing countries have a heterogeneous economy with a large number of micro-enterprises operating in the informal sector. The innovation system in developing countries is characterized by a low degree of institutional thickness and thus weak interactive learning (D'Costa 2006). Moreover, the links between informal and formal institutions seem to be weak in general (Chaminade et al. 2010).

In addition to the problems which are related to the nature of NIS concept, developing countries face several other obstacles in the race to innovation, which mainly derive from contrasting business models, poor governance and low education level.

Low educational levels: Educational levels are low in developing countries and this is a significant barrier to the development and diffusion of innovation in these countries. In fact, one can establish a clear relation between educational needs and the different phases of industrialization. In the pre-industrial phase, educational needs demand only basic literacy. In the industrial phase, more professional and medium-level skills are required. In the post-industrial phase, there is a need for a significant share of a population with tertiary education, with the rest of the population having at least functional literacy (Aubert 2004).

Weak infrastructure: There is the issue of a lack of infrastructure. Of primary importance is, of course, the telephone infrastructure and internet connection. Mobile phone technology has transformed the conditions of telecommunications in developing countries. Yet, the tele-density remains weak in a number of developing countries, inferior to what may be considered the minimal threshold for take-off (around 30 percent). Progress made with mobile phone technology can lead to rapid improvements in connectivity; however it does not solve the necessity for greater internet penetration - something which remains quite low in most developing countries. Infrastructural needs for innovation in developing countries are, however, not limited to telecom- munications. Road and other transport infrastructure are of primary importance, as well as sanitation, water, and other systems (Aubert 2004). Another problem is the lack of technological support services and infrastructure (metrology, quality control, standards, etc.).

Poor quality of the business environment. In developing countries, formal rules and laws are less well developed and, more importantly, their enforcement tends to be unreliable and arbitrary (Altenburg 2008). More generally, when judging the quality of a business environment it is of crucial importance to go beyond the formal appearance of laws, to examine how laws are applied in practice in taking due account of the more or less informal relations regulating transactions among economic agents (Aubert 2004). Altenburg (2008) stated that the results of such interference rarely stimulate innovative behaviour.

Almost inexistent innovation policy: There are only a very few developing countries that have innovation policies or strategies in place. If any, most of the innovation initiatives in developing countries are hi-tech oriented that do not meet the needs of the poor or the marginalized.

\section{SYSTEMS OF INNOVATION FOR DEVELOPMENT (SID)- A TENTATIVE TO ADAPT THE IMPLEMENTATION OF NIS IN DEVELOPING COUNTRIES}

In order to overcome the difficulties to implement NIS in developing countries, which were discussed in the previous section, in 2001, Charles Edquist, Director of the Centre for Innovation, Research and Competence in the Learning Economy (CIRCLE), Lund University, Sweden, proposed System Innovation for Developing Countries, so called System Innovation for Development (SID). The SID concept was based on the existing OECD System of Innovation (SI) however Edquist included specific measures to guarantee its applicability in developing countries.

To better understand the difference between the two approaches, in particular the difference between innovation in developed and developing countries, Edquist has laid out the different kinds of innovation in order to provide an answer what is meant by innovation in the context of a developing country. He made a useful distinction between (i) process and product innovations, (ii) incremental and radical/breakthrough innovations, (iii) development, diffu- 
sion and use/production of new processes and products, and (iv) innovation in low, medium and high technology sectors.

\section{Box 2. Different kinds of innovation}

\begin{abstract}
a. Process and product innovations and its sub-categories. Innovations may be said to be new creations of economic significance. The taxonomy of innovation divide innovations into new products and new processes, as product innovations may be goods or services. It is a matter of what is being produced. Process innovations may be technological or organizational. It concerns how goods and services are produced.
\end{abstract}

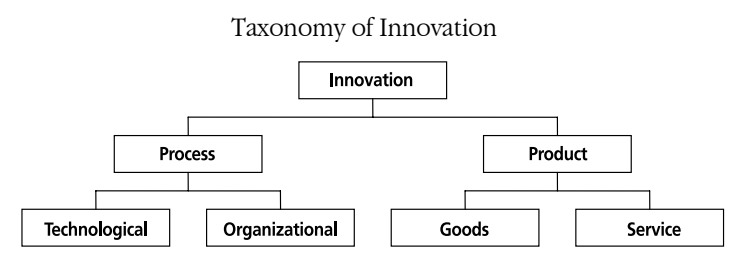

b. Incremental and radical/breakthrough innovations. Innovation cans take place in several forms:

(1) continuous small incremental changes,

(2) discontinuous radical innovations, and

(3) massive shifts in some pervasive 'general purpose technology' (GPT), sometimes called 'techno-economic paradigms.'

c. Development, diffusion and use/production of new processes and products

d. Innovations in low, medium and high technology sectors. The distinction between low, medium and high technology sectors is made in terms of R\&D intensities of the sectors.

Source: Edquist (2001)

\section{The similarity between system of innovation (SI) and system of innovation for development (SID)}

Edquist also points out that a system of innovation (SI) and a system of innovation for development (SID) have the same nine basic characteristics (listed below). For example, they place innovation at the core and they both consider the innovation process to be evolutionary, stress the differences between systems and that innovation is an interactive learning process (systemic), reject the notion of optimality, emphasize interdependence between organizational actors in a context of institutional rules, and encompass different kinds of innovations.

According to Edquist (2001), there are nine common characteristics between SI and SID approaches:

(1) They place innovation and other learning processes at the centre of focus.
(2) They adopt a holistic and interdisciplinary perspective.

(3) They use a historical perspective and consider innovation processes to be evolutionary.

(4) They stress differences between systems, and that the notion of optimality is irrelevant.

(5) They emphasize interdependence between actors - in the sense of 'players.'

(6) They include product and process innovations, as well as their development and diffusion.

(7) They emphasize the central role of institutions - in the sense of 'rules of the game.'

(8) They are associated with conceptual diffuseness.

(9) They are conceptual frameworks, rather than formal theories.

However, he argues that there are four main areas where the notion of SID diverges from SI:

(1) Product innovations are more important than process innovations because of their effect on production structure. Such structural changes are more called for in developing countries than in developed ones, simply because achieving a more advanced production structure is an immanent part of the process of development. Therefore the difference in importance between product and process innovations is larger in developing countries.

(2) Incremental innovations are more important than radical ones in developing countries, partly because they are more attainable for them. This concerns particularly countries at an early stage of development.

(3) Absorptions (diffusion) is more important than development of innovations that are new to the world. For developing countries the generation of technological capability is primarily a matter of absorbing products and processes developed in other countries and deepening their knowledge about them over time. Therefore, the diffusion and absorption of innovations are of more interest in a SID perspective than in a general SI perspective. With regard to emphasis on different kinds of innovations, this is the most important difference between the general SI approach and the SID version.

(4) Finally, innovations in low and medium technology sectors are more easily attainable in developing countries than innovations in high technology sectors. This has to do with the fact that innovations in high technology sectors are often science based and quite sophisticated. 
Despite the introduction of new elements in the SID concept, its implementation in developing countries is still difficult. Edquist (2001), himself, recognized that the implementation of this approach has a limit because many of the organizations and institutions that are instrumental and important for innovation processes are simply not in place or not appropriate in developing countries. Private organizations are often less capable of handling the absorption of innovations than firms in developed countries. Meaning that private organizations (including firms) do not produce enough innovation-based economic growth and welfare. In addition, many public organizations of innovation relevance are insufficiently integrated with other organizations in the system. Also formal institutions, like legal frameworks and incentive systems, and informal institutions like business practices and norms governing collaboration between firms are often less appropriate in developing countries. As the concept was developed based on the NIS, so SID maintains the same constrain that the NIS has.

\section{INCLUSIVE INNOVATION - PRO-POOR INNOVATION}

The main issue in developing countries is poverty with a large percentage of people having limited access to basic services such as food, water, housing, health and education. Innovation can be a critical tool to overcome these challenges. What is needed is not only to reduce costs and increase the availability of goods and services, but more importantly to encourage sustainable livings and produce income-generating opportunities for the poor. Furthermore, innovation, through access to new and existing technology, can help create more and better paying jobs.

During the last decades, there has been an increase in interest of the role of innovation in developing countries. Unfortunately, with some exceptions, they do not systematically address reducing poverty or socially inclusive types of innovation because the innovation in formal sector was designed to achieve economic growth and competitiveness and not to reduce poverty (Kaplinsky 2010; STEP Centre 2010).

At least during the last several years, we witnessed the growth of interest in pro-poor innovation. This has been reflected by the growing body of literature dealing with this subject. Iizuka and SadreGhazi (2011) explain that the growing attention to "pro-poor innovation" is related to the current transformation of global challenges that requires a different approach to search for the possible solutions. First, there is an enlarging role of developing countries as new producers and markets. Second, there is a growing global awareness that the widening gap between those who have and those who do not have has been endangering long term sustainability not only for the developing countries but also for developed countries. Third, conventional approaches to international aids and their effectiveness are being widely questioned. Fourth, innovation capability, together with science and technology, are increasingly highlighted as important elements not only for the economic growth but also for poverty alleviation.

A pro-poor innovation system can be defined as a multi-stakeholder social learning process that generates new knowledge, puts it to use, and expands the capabilities and opportunities of the poor (Berdegué 2005). Inclusion of the poor in every step of innovation process is the key of success in pro-poor innovation concept. Inclusion can take place by building the capacity of the poor to produce what they already know how to and do produce, as well as building the capacity of the poor to use their innovations and outstanding traditional knowledge (World Bank 2010).

An important means of encouraging inclusive innovation is to support grassroots innovation networks and indigenous and traditional knowledge initiatives and to promote and diffuse their innovations (World Bank 2010). Grassroots innovation is primary a bottom-up approach of pro-poor innovation (Gupta 2010). It is networks of activists and organizations that generate novel bottom-up solutions for sustainable development: solutions that respond to the local situation and the interests and values of the communities involved (Seyfang and Smith 2010).

The output of a grassroots innovation is a product that caters to the local need, by offering simple-to-operate products that are transformed or no-frills versions of an existing product category. Some of them are based on indigenous knowledge, like medicine. However, such innovations are centred on a product/invention and face similar obstacles in terms of diffusion and scaling up.

Anil Gupta (2009) states that the grassroots method can help the organized (formal) sector learn from grassroots 
innovators and traditional knowledge holders to solve problems in an affordable, accountable and accessible manner. He explains that there are three main reasons: first, the lack of material resources spurs knowledgeintensive innovations by common people in the informal sector and thus provides a basis for sustainability by reducing entropy; second, the grassroots innovations are important not only because they are low cost and maintainable at local levels, but also because they offer the problem solving techniques which can be applied in different contexts; and third, several of these innovations can be blended.

The implementation of the grassroots innovation concept has several limitations, among others:

- For instance, to encourage formal creation and commercialization efforts that focus on the challenges facing the poor, it can be very difficult to find private companies that will invest in this kind of innovation because there is no economic guarantee. Thus, funding is dependent on government subsidization. Observing many failure cases of the grassroots initiatives, policy-makers are reluctant to support these ventures.

- There are five main challenges regarding the implementation of grassroots innovation: high transaction costs of scouting and documentation, the need for value addition, for commercialization, and for finance; and unclear intellectual property rights (Utz and Dahlman 2007). These challenges make the implementation of grassroots innovation very difficult.

- Hua et al.(2010) state that individual grassroots innovation in China still faces great difficulties, due to: (i) lack of policy measures to support grassroots innovation, (ii) limited capacity of grassroots inventors and lack of inter-related social network among them, (iii) no existence of a financial system to support the grassroots innovation; (iv) the products of grassroots innovation are relatively simple (low technology) and therefore easy to imitate, which mainly make the protection of the intellectual property rights very difficult. It constrains the benefits of China's grassroots innovation to a large extent.

- The sustainability of the activities that help informal enterprises better absorb existing knowledge is questionable as it depends on government incentives that provide resources of knowledge.
Box 3. India's experience in promoting inclusive innovation

Recognizing the importance of innovation, the President of India has declared this decade as the 'Decade of Innovation,' with a focus on inclusive growth. In relation to the Indian Decade of Innovation, the Office of the Adviser to the Prime Minister of India has published a strategic paper entitled Towwards a More Inclusive and Innovative India: Creating a Roadmap for a Decade of Innovation (2011).

To accelerate the implementation of inclusive innovation the Office of Adviser to Prime Minister of India has recommended the following measures: (i) establishing (national, state and sectoral) innovation councils to prepare a roadmap for inclusive innovation for the decade of 2010 - 2020; (ii) establish an Inclusive Innovation Fund of $\$ 1$ billion, to encourage commercialization, venture capitals and angel investors; (iii) develop 20 innovation clusters for the year 2020; (iv) create a national innovation portal; (v) establish multiple roadmaps that will be used as policy inputs for the government concerning innovation; (vi) facilitate the creation of an innovation eco-system; (vii) provide the right mechanisms for collaboration, training and support to drive innovation; (viii) focus on core competencies and (ix) encourage innovators by awarding prizes in innovation.

In India, the NGOs have also been playing and important role in promoting inclusive innovation by filling in the gaps which the government and industry have still not addressed. Among the wellknown Indian NGOs include the Honey Bee Network (HBN), the Society for Research and Initiatives for Sustainable Technologies and Institutions (SRISTI), Gujarat Grassroots Innovation Augmentation Network (GIAN), Sustainable-Agriculture and Environmental Voluntary Action (SEVA), and Rural Innovation Network (RIN).

The HBN, founded and led by Prof. Anil Gupta, consists of innovators (individuals, farmers, and entrepreneurs), policy makers, academics, and NGOs committed to recognizing and rewarding innovative ideas and traditional knowledge produced at the grassroots level (by individuals and communities) through local language interfaces. It seeks to protect the intellectual property rights of knowledge holders and follow the conditions they may advise under the concept of prior informed consent.

\section{MOVING TOWARDS AN INTEGRATED TECHNOLOGICAL INNOVATION APPROACH IN DEVELOPING COUNTRIES}

The discussion in the previous sections shows us that there are many challenges to promote both firm based and grassroots innovation in developing countries. This section will discuss about a new strategy for promoting innovation in developing countries that can overcome the difficulties in 
putting in place NIS, SID and inclusive innovation. The strategy should be able to create a synergy among very high diversity of the innovation stakeholders in developing countries. It requires having a capacity to foster the investment in advanced technology and promote the development of affordable technology to meet the need of the poor, as well as to develop, attract and retain strong talents for innovation.

Compared to developed countries, the concept innovation system in developing countries should be more complex because it is not only involving the formal sector such as enterprises, universities, research institutes, the government and the financial system but also NGOs, informal companies, grassroots inventors, local and indigenous knowledge, etc. The implementation of such a concept is also more difficult because the formal rules and laws are less well developed, their enforcement tends to be unreliable and they have less effective accountable governance. The innovation system in developing countries is situated in a dichotomy situation between formal and informal sector, between riche and poor, and between high and low technology. The main challenges in the governance of such an innovation system are to meet the needs of both the formal and informal sectors of economy. On the one hand, the innovation system should allow private companies to generate wealth and, on the other hand, it should also be able to improve the living conditions of the poor. The innovation system in developing countries should not exclude R\&D in advance technology.

Below, I describe the basic and preliminary ideas that facilitate the elaboration of an integrated approach in promoting technological innovation in developing countries.

\section{Strengthening national innovation policies}

First and foremost, developing countries need to set up their innovation policy with targets and priorities that are based on the specific challenges and opportunities faced by the country concerning innovation. An innovation policy is an instrument to move towards a knowledge economy. It addresses specific problems of the innovation system, such as its rules and regulations conducting innovation to ensure competition, determine levels of entry and exit of firms, and allow financial markets to provide appropriate signals to investors (Altenburg 2008). Furthermore, innovation policy is crucial for development, at least for two reasons: (i) innovation and learning -understood in broad sense- are fundamental for growth and industrial competitiveness and thus for catching-up; and (ii) innovation can be targeted to solve or mitigate particular development problem (Chaminade et al. 2010).

To move towards achieving a holistic architecture of innovation policy design and implementation, broad-based societal participation must be mobilized. Reflecting the global trend towards achieving a greater democratization and transparency in the decision making process, citizens are becoming engaged in the deliberative processes of science-related governance issues. In this context, decision makers, entrepreneurs, scientists, NGOs, including women, youth, local and indigenous communities, are not only considered beneficiaries of the innovation, but also agents of change of the innovation system.

The other problem related to innovation policy is that developing countries tend to have limited capabilities to design, implement and monitor complex innovation policies. The situation is even more difficult because most developing countries do not have a special institution dealing specifically with innovation policy. Thus, special emphasize has to be given to human and institutional capacity building for innovation policy. The existence of national and regional bodies that deal with innovation policy formulation, monitoring and its evaluation is very important to ensure the effectiveness of the policy. It could be an innovation council or innovation institute. Innovation research institutes are also crucial as once innovation polices have been made they should be subject to continuous monitoring and evaluation.

\section{Improving $R \& D$ capacities}

Research and development (R\&D) activities in developing countries is very low. It is related to the low investment in STI. Very little attention is paid to S\&T research by low income developing countries because it is considered a longterm investment with very low return which results in weak R\&D capacities. In order to improve their research systems, developing countries need to increase their investment in STI, particularly in two fields: building the capacity of human resources and upgrading or modernizing the research infrastructure. Capacity building is central for absorption and acquisition of knowledge and technology, which are both very important processes precedingthe technological innovation capacity. Innovation and capacity building in most developing countries would benefit from upgrading the skills of workers and farmers and from training more skilled workers and technicians. This can be done by formal education and training, but also by diffusing the concept of learning organizations among firms; the diffusion should function 
as heuristic device for local firms' experimentation within specific context of learning organizational form (Chaminade et al. 2010).

Universities and other higher educational institutions are essential players in a country's innovation system. Universities produce well-trained human resources and conduct research that generates knowledge for innovation. In general, in developing countries universities focus more on education and do little R\&D. Universities in many developing countries like India, Indonesia, Colombia and other developing countries, already have the critical mass of scientists and have considerable intellectual capital that can be deployed to work on the technological problems of the poor. Universities could eventually play an important role in dealing with social, economic and environmental challenges. For example, there is a great opportunity for universities and research centres to conduct R\&D to support grassroots innovation initiatives and to develop technology business incubators and science parks to host small and medium enterprises (SMEs).

\section{Enhancing the innovation capacity of firms}

The enterprise sector in developing countries is a large part composed of micro-enterprises which operate in the informal economy and which have a very low technology competency, if any. A less important segment is composed of SMEs with minimal technological capabilities. An even smaller segment is constituted of technology competent enterprises. Finally, there is small number of R\&D rich enterprises (Aubert 2004). Thus, a specific approach is needed to enhance the innovation capacities of firms in developing countries. The approach should take into consideration the diverse nature of the existing enterprises. A board range of support network, including research centers, universities, firms and NGOs, need to mobilize to accelerate the absorption of technology by micro enterprises and SMEs.

Engaging in interactive learning with other organizations of the system is fundamental for development on innovation. There are thee linkages which are more important than others: (i) the interaction between indigenous firms and subsidiaries of multinationals to facilitate technology transfer; (ii) the interaction between domestic users and producers to create the condition of trust in absorption of technology; and (iii) the interaction between industry and domestic universities for the provision of human resources (Chaminade et al. 2010).

\section{Supporting the creation of knowledge-based SMEs: science parks and technology business incubators}

The common tools that have been used to promote the creation of knowledge-based SMEs are technology business incubators and science parks. They play a crucial element of national, regional and local innovation system. Technology business incubators are part of the basic infrastructure that supports start up SMEs by providing the physical infrastructure (facilities and rental spaces), professional services advice (management, tax, accounting, technological lectures, etc.), financial support (seed money, access to venture capital, etc.), training and mentoring. The aim of business incubation is to increase the success ratio of start-up firms even if the incubator is not a definitive place for the SMEs. The mature (graduated start-up) companies must relocate to a science park. The existence of a science park is very important to facilitate networking for innovation. It aims to enhance the innovative capacity and foster the enterprises through the interaction and close linkage among government, R\&D centres, research institutes, high-tech industry: initiating university and industry partnerships, launching commercialization, marketing and providing financial support.

During the last several decades, we have been witnessing that science and technology parks play an important role in advancement of the various fields of technology, such as information and communication technology, biotechnology, nanotechnology, electronics, etc. Many developing countries have also taken the initiative in developing science parks and incubators. However, many of them face problems, such as low successful rate of incubator tenants, very slow advancement of innovation, etc. I think the main cause of the problem is that there is too much focus on hi-tech, which is based on R\&D, in which the developing countries have limited capacity. The potential of grassroots innovation, local and indigenous knowledge are not very well exploited. I suggest that the technology business incubators and science parks in developing countries should not only host hi-tech start-up companies, but also accommodate low-tech start-ups.

\section{Promoting grassroots innovation}

Grassroots innovation has an immense potential to be used as a tool for poverty eradication because it is based on local people's knowledge, innovations, and practices that are largely produced and maintained at the grassroots level. Furthermore, the grassroots technological innovations are 
needs-based, simple and cost-effective. Our understanding and policies for innovation is inadequate for grassroots community initiatives. Research is needed to develop our understanding of local communities as sources of sustainable innovations.

Currently, there are many successful grassroots technological innovations however the economic impact of these innovations is low. There is therefore a need to build a value chain around these innovations and to provide incubation support, if the benefits from these innovations are to be disseminated to consumers far and wide. To this end, we need to mobilize a broad range of actors, including governments, NGOs, the private sector and local communities. NGOs have an important role to play in the innovation system, particularly as policy implementers and drivers of change in promoting grassroots innovation. NGOs can play their part by creating platforms that assist grassroots innovators diffuse information to people who do not have access. The involvement of NGOs will also accelerate the process of the technological appropriation by local community.

\section{Creating a financial system for Innovation}

In the OECD member countries, thousands of venture capital funds operate to finance knowledge-based start-up companies. The objective of the venture capital investor is to invest in rapidly growing companies in order to sell out (typically after five to eight years), either to another entrepreneur, other parties or the stock market. The high risk of this type of investment is compensated by the high return on successful ventures. Many venture capital funds do not only provide capital. They also support the young entrepreneurs by closely monitoring them and providing technical and managerial support. Those aimed specifically at new startups almost always provide such support.

Unfortunately such financial systems do not exist in developing countries. In general, it is extremely difficult for SMEs to obtain finance, and certainly equity. Financial institutions are not interested in investing in start-up companies because there is no guarantee, high risk and the run cost of the credit is expensive. However, it is necessary to establish an appropriate financial system to support knowledge-based start-up companies in developing countries.

Finally, an innovation system has to accommodate the interchanges and connectivity among the stakeholders that have the common objective to move towards a knowledgebased society.

\section{CONCLUSION}

The main challenge in developing countries is poverty. Innovation can be a critical tool to solve this challenge and to improve access to basic services such as food, water, housing, health and education. However, in general, their current innovation systems are poorly constructed and are very fragmented which is characterized by poor business, the inexistence of research centers or a very limited research community, low education levels, weak infrastructure, inefficient public institutions, poor governance and the inexistence of an innovation policy or strategy.

The implementation of the existing innovation concepts in developing countries needs to be done carefully, by taking into consideration of the local conditions. Developing countries need to move towards achieving a more structured innovation system based on an established innovation policy. An innovation system, which can accommodate the interaction among the high varieties of stakeholders, such as enterprises, universities, research institutes and government, financial system, NGOs, informal companies, grassroots inventors, local and indigenous knowledge, etc. must be developed.

An integrated approach is needed to establish an appropriate innovation system in developing countries. An innovation system which is based on relevant innovation policies, able to accommodate both advanced innovation and grassroots innovations, involves the formal and informal sector and that aims to improve the quality life.

\section{REFERENCES}

Aubert, J-E. (2004) Promoting innovation in developing countries: A conceptual framework, World Bank Policy Research Working Paper 3554 (Washington, DC: World Bank Institute).

Altenburg, T. (2008) "Building inclusive innovation systems in developing countries - why it necessary to rethink the policy agenda," paper presented in the $6^{\text {th }}$ GLOBELIC International Conference, September 2224, 2008. Mexico City, Mexico.

Arocena, R., and Sutz, J. (2000) "Looking at national systems of innovation from the South," Industry and Innovation $7(1): 55-75$.

Berdegué, J. A. (2005) Pro-Poor Innovation Systems (Rome: International Fund for Agricultural Development). 
available online http://www.ifad.org/events/gc/29/ panel/e/julio.pdf.

Bell, M. (2007) Technological learning and the development of production and innovative capacities in the industry and infrastructure sectors of the least developed countries: What role for $O D A$ ? A paper prepared for UNCTAD (Brighton, UK: SPRU, University of Sussex).

Chaminade, C., Lundvall, B-A., Vang-Lauridsen, J., and Joseph, K.J. (2010) Innovation policies for development: towards asystemics experimentation based approach, Paper No. 2010/01, CIRCLE Electonic Working Papers (Lund, Sweden: CIRCLE, Lund University).

D'Costa, A. (2006) Export, university-industry linkages an innovation challenges in Bangalore, India, World Bank Policy Research Working Paper 3887 (Washington, DC: World Bank Institute).

Edquist, C. (2001) Systems of innovation for development. Background paper for Chapter 1: Competitiveness, Innovation and Learning: Analytical Framework for the UNIDO World Industrial Development Report (WIDR), 2001 available online http://www.unido.org/fileadmin/ import/userfiles/hartmany/idr-edquist-paper-draft2.pdf.

Freeman, C. (1987) Technology policy and economic performance: Lessons from Japan (London: Pinter Publishers).

Godin, B. (2007) National Innovation System: The system's approach in historical perspective, Working Paper No. 36, Project on the History and Sociology of STI Statistics (Montreal, Canada).

Gupta, A.K. (2009) "Grassroots Green Innovations for Inclusive Sustainable Development," in A. Lopez-Calos (ed.), The Innovation for Development Report 2009 2010 Strengthening Innovation for the Prosperity of the Nations (New York: Palgrave Macmillan), 23-32.

Gupta, A.K. (2010) Leveraging Innovations for Inclusive Governance. Working Paper 2010-10-01. (Ahmedabad. India: Indian Institute of Management)

Hua,L, Jiang, Y., and Lin, Y. (2010) Grassroots innovation, characteristics, status quo and suggestion, in proceeding of the $7^{\text {th }}$ International Conference on Innovation Management, Wuhan University of Technology, China, December 4-5, 2010.

Iizuka, M., and SadreGhazi, S. (2011) Understanding dynamics of pro-poor innovation : Mapping the disputed areas, presented at the DIME Final Conference, April 6-8, 2011. Maastricht, p. 20.
Kaplinsky, R. (2011) "Schumacher meets Schumpeter: Appropriate technology below the radar," Research Policy 40(2): 193-203.

Kaplinsky, R., Open, T., and Clark, N. (2009) "Below the radar : what does innovation in emerging economies have to offer other low-income economies?" International Journal of Technology Management and Sustainable Development 8(3): 177-97.

Lundvall, B-A.(ed.) (1992) National systems of innovation (London: Anthem Press).

Lundvall, B-A.(2000) "Introduction," in Edquist, Charles and Maureen McKelvey (eds.), Systems of Innovation: Growth, Competitiveness and Employment, an Elgar Reference Collection (Cheltenham, UK: Edward Elgar Publishing).

Lundvall, B-A., and Borrás, S. (2005) "Science, Technology, and Innovation Policy," in Fagerberg, J., Mowery, D. C. and Nelson, R. R.(eds), The Oxford Handbook of Innovation (New York: Oxford University Press), 599-631.

Lundvall, B-A., Joseph, K.J., Chaminade, C., and Vang, J.(2009) Handbook of innovation and developing countries: Building domestic capabilities in a global setting (Cheltenham, UK: Edward Elgar Publishing).

Nelson, R. R.(ed.) (1993) National Innovation Systems (New York: Oxford University Press).

Office Advisor to Prime Minister of India. (2011) Towards a More Inclusive and Innovative India - Creating Roadmap for a Decade of Innovation, Strategic Paper (New Delhi, India: Prime minister's office)

Pietrobelli, C., and Rabellotti, R.(2009) "The global dimension of innovation system: linking innovation system and global value chains," in Lundvall, B-A., et al. Handbook of innovation and developing countries: Building domestic capabilities in a global setting, (Cheltenham, UK: Edward Elgar Publishing), 214-38.

STEPS Centre. (2010) Innovation, Sustainability, Development: A New Manifesto (Brighton, UK: The STEPS Centre (Social, Technological and Environmental Pathways to Sustainability)).

Seyfang, G., Smith, A., and Longhurst, N. (2010) "Grassroots Innovations for Sustainable Development: a New Research Agenda," Economic sociology: the European electronic newsletter 12(1): 67-71.

Utz, A., and Dahlman, C. (2007) "Promoting inclusive innovation in India," in Dutz, M.A. (ed.), Unleashing India's Innovation: Toward Sustainable and Inclusive Growth (Washington, DC: World Bank Institute), 105-28. 